\title{
Olivier Lumbroso, Zola autodidacte. Genèse des œuvres et apprentissages de l'écrivain en régime naturaliste
}

\section{Maria Emanuela Raffi}

\section{(2) OpenEdition}

1 Journals

\section{Edizione digitale}

URL: http://journals.openedition.org/studifrancesi/1589

DOI: 10.4000/studifrancesi. 1589

ISSN: 2421-5856

\section{Editore}

Rosenberg \& Sellier

\section{Edizione cartacea}

Data di pubblicazione: 1 novembre 2014

Paginazione: 626

ISSN: 0039-2944

\section{Notizia bibliografica digitale}

Maria Emanuela Raffi, « Olivier Lumbroso, Zola autodidacte. Genèse des œuvres et apprentissages de l'écrivain en régime naturaliste », Studi Francesi [Online], 174 (LVIII | III) | 2014, online dal 01 novembre 2014, consultato il 18 septembre 2020. URL : http://journals.openedition.org/studifrancesi/1589 ; DOI : https://doi.org/10.4000/studifrancesi. 1589

Questo documento è stato generato automaticamente il 18 settembre 2020.

\section{(c) 9 (i) $\Theta$}

Studi Francesi è distribuita con Licenza Creative Commons Attribuzione - Non commerciale - Non opere derivate 4.0 Internazionale. 


\title{
Olivier Lumbroso, Zola autodidacte. Genèse des cuvres et apprentissages de l'écrivain en régime naturaliste
}

\author{
Maria Emanuela Raffi
}

\section{NOTIZIA}

OLIVIER LUMBROSO, Zola autodidacte. Genèse des cuvres et apprentissages de l'écrivain en régime naturaliste, Genève, Droz, 2013, pp. 423.

1 Dopo un'introduzione dedicata alle possibilità teoriche e alle forme di esistenza di un «apprentissage de l'écrivain» e più specificamente dell'«auto-apprentissage» di Zola, l'A. propone «une approche génétique diachronique autant que dialogique des dossiers préparatoires des Rougon-Macquart». L'itinerario attraverso il formarsi della scrittura di Zola avviene in quattro fasi successive, ciascuna corrispondente a un capitolo.

2 Nel primo («Le Métier d'écrivain: de la formation littéraire à l'invention de soi») Lumbroso prende in esame la riflessione di Zola sulla sua esperienza del sistema scolastico, che lo scrittore avrebbe voluto più «varié et généreux». A tale sistema si contrappone la sua formazione di autodidatta, che progredisce e sviluppa la propria conoscenza in modo autonomo, inclusa anche una «acclimatation sociale» spesso difficile e dolorosa e una strategia di affermazione di sé a volte febbrile.

Nelle pagine di critica letteraria di questo periodo di formazione appare comunque chiara per l'A. la doppia distanziazione di Zola dall'ispirazione romantica - critiche a Doré - e dallo spirito troppo sistematico - limiti del metodo di Taine -, anche se l'influenza di Taine tenderà a diventare determinante dopo il 1866.

Il secondo capitolo («Les dossiers préparatoires ou la pensée 'en travail'») appare centrale nello studio di Lumbroso; in esso si concentra un attento e preciso studio della struttura di base dei dossiers, delle particolarità della pratica preparatoria zoliana e soprattutto dell'evoluzione tecnica che essa mostra nel susseguirsi dei vari romanzi. 
L'A. vuole porre l'accento su quest'ultimo aspetto - «le dossier dans son instabilité» - , considerando la scrittura preparatoria di Zola come «métatexte». È in questa prospettiva che l'A. articola la sua dettagliata analisi dell'«avant-texte» dei RougonMacquart, che occupa tutta la parte centrale del saggio («Le développement du métalangage au fil du cycle»).

«De la rhétorique à la poétique: les dossiers préparatoires 'au travail'», terzo capitolo, prende in esame «les modèles génératifs», veri e propri modelli ritmici della produzione narrativa zoliana: «le schéma aristotélicien», strutturato come una tragedia classica, «le schéma alternatif», costruito su un 'crescendo' narrativo, «le schéma 'à tiroirs'», modellato sul concetto di 'serie' di oggetti e personaggi, «le schéma par 'couches continues'», con interventi successivi e graduali, «le schéma catastrophiste» che tratteggia un dramma di dimensioni collettive e sociali, «le schéma cyclique» fondato sulla ripetizione degli avvenimenti cruciali.

6 La presenza più o meno forte e accentuata dei modelli generativi dà luogo, lungo tutta la raccolta dei Rougon-Macquart, a dei fenomeni di hypertension e di hypotension accuratamente registrati da Lumbroso, mentre lo studio della «dispositio» lo porta a catalogare fenomeni di scrittura legati al ritmo: vibrazioni, «plongeons», «résonances», «dédoublements», «dissonances». L'elemento temporale (dilatazioni, ellissi, concentrazioni) influisce a sua volta sulla tensione narrativa e determina spostamenti significativi di ritmo.

7 Nell'ultimo capitolo dello studio («Mythographie du dossier préparatoire. Les fantasmes du créateur à l'œuvre») Lumbroso si sofferma sul procedimento di «mise en abyme», cioè di introduzione nel testo dell'autore, delle sue allegorizzazioni o dei luoghi simbolici della sua presenza. Anche nei dossiers préparatoires Zola mostra la sua presenza diretta, iscrivendo considerazioni di meta-scrittura, ma il rapporto fra testo e avant-texte su questo punto si rivela piuttosto conflittuale e a volte drammatico: «Un scénario tragique, un fantasme obsédant de dépossession révèle un imaginaire du 'manuscrit brisé' [...]: cet imaginaire traverse son œuvre dans son épaisseur et sur toute sa longueur et éclaire autrement la chambre oscure de la création littéraire».

8 Partito dal progetto generale di volersi misurare con ciò che resiste come strategia di conoscenza, Zola mostra in questo studio di Lumbroso i modi e le forme della sua formazione di scrittore, nella complessa traiettoria che lo porta dai dossier alla sua vasta opera narrativa. 